\title{
COPING MECHANISM MAHASISWA BARU DALAM MENGHADAPI PROGRAM PENGENALAN KEHIDUPAN KAMPUS DI POLTEKKES RS dr.SOEPRAOEN MALANG
}

\author{
Dian Pitaloka Priasmoro ${ }^{1}$,Aloysia Ispriantari² \\ 1,2 Dosen Program Studi D-III Keperawatan Poltekkes RS dr.Soepraoen Malang
}

(Korespondensi: priasmoro.pitaloka@gmail.com)

\begin{abstract}
ABSTRAK
Pendahuluan Program Pengenalan Kehidupan Kampus adalah suatu kegiatan yang terprogram dan dikelola dengan baik yang bertujuan agar mahasiswa menyesuaikan diri dengan lingkungan kampus dan sistem pendidikan tinggi yang akan mereka jalani selama studi. Beberapa penelitian mengungkapkan mahasiswa baru yang akan menjalani program pengenalan studi mengalami kecemasan dan melakukan tindakan pengalihan yang bermacam-macam atau disebut coping mechanism. Penenelitian ini bertujuan untuk mengetahui coping mechanism mahasiswa baru dalam menghadapi program pengenalan kehidupan kampus di Poltekkes RS dr.Soepraoen Malang. Metode dalam penelitian ini adalah deskriptif. Populasi dalam penelitian ini adalah seluruh mahasiswa baru prodi keperawatan yang menjalani program pengenalan kehidupan kampus sejumlah 170. Sampel dalam penelitian ini adalah sebagian mahasiswa baru yang menjalani program pengenalan kehidupan kampus sejumlah 119 yang diambil secara stratified random sampling. Penelitian ini dilakukan di Poltekkes RS dr.Soepraoen Malang Pada bulan Agustus 2018. Hasil penelitian menujukkan coping mechnism mhasiswa baru hampir seluruhnya adaptif sebanyak 118 orang $(99,2 \%)$ dan sebagian kecil maladaptif sebanyak 1 orang $(0,8 \%)$. Diskusi Hal ini kemungkinan disebabkan karena usia, pola asuh, pekerjaan orang tua, dan jenis kelamin responden. Kesimpulan Dari hasil diatas pihak institusi dapat bekerja sama dengan orang tua untuk memberikan dukungan sehingga mahasiswa akan menyikapi sumber stresor secara lebih adaptif.
\end{abstract}

Kata kunci : coping mechanism, mahasiswa baru, program pengenalan kehidupan kampus.

\begin{abstract}
Introduction Campus Life Introduction Program is a well-programmed and managed activity that aims to make students adjust to the campus environment and the higher education system they will facing during the study. Some studies reveal that new students who will facing the program they experience anxiety and carry out diversionary actions that are various or called the coping mechanism. This study aims to determine the coping mechanism of new students in facing the program of introducing campus life in the Polytechnic of RS Dr. Soepraoen Hospital, Malang. Methode in this study is descriptive. The population in this study were all new nursing study program students who underwent a program of introduction to campus life in a number of 170 . The sample in this study was that some of the new students who underwent a program of introduction to campus life were 119 taken by stratified random sampling. This study was conducted at the Dr. Soepraoen Malang Hospital Polytechnic in August 2018. Results of the study showed that the coping of new students was almost entirely adaptive as many as 118 people $(99.2 \%)$ and a minority maladaptive as many as 1 person $(0.8 \%)$. Discussion This might be due to age, parenting, parent's work, and the sex of
\end{abstract}


the respondent. Conclusion From the above results the institution can work together with parents to provide support so that students will respond to stressor sources more adaptively.

Keywords: coping mechanism, new students, campus life recognition program.

\section{PENDAHULUAN}

Program Pengenalan Kehidupan Kampus adalah suatu kegiatan yang terprogram dan dikelola dengan baik yang bertujuan agar mahasiswa menyesuaikan diri dengan lingkungan kampus dan sistem pendidikan tinggi yang akan mereka jalani selama studi (Bidang Kemahasiswaan Poltekkes RS dr.Soepraoen Malang, 2017). Paradigma lama kegiatan Pengenalan Kehidupan Kampus bagi mahasiswa baru yang pada masa lalu diwarnai oleh perpeloncoan dipandang perlu untuk dirubah.

Nugroho (2017) menjelaskan bahwa dari 60 orang mahasiswa baru yang akan mengikuti program pengenalan studi hampir setengahnya sebanyak 53 orang $(57 \%)$ mengalami cemas ringan sampai sedang. Sedangkan dari studi pendahuluan yang pada bulan September 2017 yang diwawancara 8 orang mengatakan merasa tertekan, tidak nyaman, sering dimarahi oleh senior.

Untuk mewujudkan perubahan dalam kegiatan pengenalan kehidupan kampus perlu suatu panduan teknis yang mengikat semua pelaksana, peserta, dan pengawas dalam sebuah sistem dan tata aturan kerja yang disusun berdasarkan Jurnal Kesehatan Hesti Wira Sakti kesepakatan bersama yang berpedoman kepada SK Dirjen Dikti No. 38/DIKTI/Kep/2000 tentang pengaturan kegiatan penerimaan mahasiswa baru dan panduan umum Pengenalan Kehidupan Kampus bagi mahasiswa baru. Yang dikeluarkan oleh Kemendtrian Riset, Teknologi, dan perguruan tinggi Republik Indonesia Nomor . 096/B1/SK/2016 tentang Panduan Umum Pengenalan Kehidupan Kampus Bagi Mahasiwa Baru. Dengan demikian proses pengenalan kehidupan kampus ini dapat berjalan dengan baik. Dari uraian diatas maka peneliti tertarik untuk mengidentifikasi 'Coping Mechanism Mahasiswa Baru Dalam Menghadapi Program Pengenalan Kehidupan Kampus Di Poltekkes RS dr.Soepraoen Malang

\section{METODE PENELITIAN}

Desain dalam penelitian ini adalah deskriptif. Pendekatan yang dipakai dalam proses penelitian ini adalah survey. Populasi dalam penelitian ini adalah semua Mahasiswa Baru (TK I) Prodi Keperawatan di Poltekkes RS dr.Soepraoen Malang sejumlah 170 orang. Teknik sampling yang digunakan Stratified random sampling dan didapatkan sampel sejumlah 119 responden.

Vol 7 no 2 tahun 2019 
Instrumen yang digunakan adalah Kuisioner Ways of coping dari Lazarus dan Folkman (1988). Penelitian dilakukan di Poltekkes dr.Soepraoen dengan pengisian kuisioner selama 45 menit. Data yang didapat selanjutnya dilakukan analisis univariat dan disajikan dalam bentuk distribusi frekuensi.

\section{HASIL PENELITIAN}

Hasil penelitian didapatkan data umum responden meliputi umur sebagian besar responden 19 tahun $(51,1 \%)$, jenis kelamin responden sebagian besar perempuan $91 \quad(76,5 \%)$, kepribadian responden sebagian besar tertutup sebanyak $82(68,9 \%)$, pola asuh orang tua responden sebagian besar demokratis sebanyak 103 (86,6\%). Pekerjaan orang tua sebagian besar bukan keluarga TNI/POLRI sebanyak 66 (56\%).

Sedangkan data khusus responden didapatkan data:

Tabel 1. Gambaran Coping Mechanism

\begin{tabular}{lccl}
\hline \multirow{2}{*}{ No } & \multicolumn{2}{c}{ Mekanisme Koping } & Total \\
\cline { 2 - 3 } & \multicolumn{1}{c}{ Adaptif } & \multicolumn{1}{c}{ Maladaptfi } \\
\hline 1. & $118(99,2 \%)$ & $1(0,8 \%)$ & 119 \\
& & $(100 \%)$ \\
\hline \\
\multicolumn{3}{l}{ (Sumber : Output Pengolahan Data SPSS Juli } \\
2018)
\end{tabular}

Berdasarkan tabel 1. diatas diketahui mekanisme koping mahasiswa baru hampir seluruhnya adaptif sebanyak 118 orang $(98,2 \%)$. Dan sebagian kecil mal adaptif sebanyak 1 orang $(0,8 \%)$.

\section{PEMBAHASAN}

Berdasarkan tabel 1. diatas diketahui mekanisme koping mahasiswa baru hampir seluruhnya adaptif sebanyak 118 orang $(99,2 \%)$. Dari data umum hasil penelitian juga didaptkan bahwa hampir berumur antara 18-20 tahun. Menurut hasil penelitian ini diasumsikan bahwa mahasiswa dikatakan sudah cukup umur dan matang dalam berfikir dan mencari pemecahan masalah dalam mengahdapi suatu stressor atau masalah. Menurut asumsi peneliti bahwa seluruh responden tidak menyikapi P2KK sebagai suatu stressor yang mengancam sehingga responden mencari pemecahan masalah dengan adaptif. Asumsi peneliti sejalan dengan Yusuf (2014) yang menjelaskan tentang psikologi perkembangan, bahwa mahasiswa pada rentan usia 18 sampai 25 tahun dapat digolongkan pada remaja akhir sampai masa dewasa awal. Dan dari aspek perkembangan tugas perkembangan pada usia remaja sampai dewasa awal ini adalah pemantapan pendirian hidup. Sehingga dapat diasumsikan bahwa mahasiswa sudah memilih jalan hidupnya termasuk pemilihan profesi yaitu sebagai tenaga kesehatan dengan segala konsekuensinya termasuk menjalani proses awal memasuki kehidupan di PT yaitu melalui P2KK.

Vol 7 no 2 tahun 2019 
Berdasarkan data umum penelitian diketahui sebagian besar pola asuh orang tua yang bukan TNI/Polri demokratis sebanyak 103 orang (86,6\%). Hasil penelitian ini diasumsikan bahwa orang tua mendidik anak dengan cara yang demokratis akan membentuk kepribadian yang lebih terbuka dalam menerima masukan atau kritikan orang lain. Hal ini akan sangat menguntungkan dalam pembentukan karakter anak dimana anak akan lebih mudah menerima segala macam permasalahan yang dihadapi.

Selain itu dari pekerjaan orng tua responden didapatkan bahwa sebagian besar bukan keluarga TNI/POLRI. Teori ini diasumsikan peneliti bahwa responden bukan keluarga TNI/Polri akan lebih bebas dalam menentukan pilihan sehingga anak akan terbiasa menentukan keputusannya sendiri dan berdampak pada kematangan pola pikir anak dan membentuk anak lebih adaptif.

Asumsi peneliti ini sejalan dengan Baramuli (2014) yang menyatakan bahwa keluarga TNI/Polri cenderung menerapkan sikap dan perilaku kepada anak secara otoriter karena merasa sebagai pemimpin dalam keluarga. Sehingga ayah berhak bahkan memiliki kewenangan atau berkuasa sepenuhnya melakukan apa saja sesuai dengan keinginannya, dan tentu saja anak-anak mengalami tekanan-tekanan didalam batinnya.
Sedangkan 1 orang responden $(0,8 \%)$ yang mekanisme kopingnya mal adpatif diketahui bahwa responden berjenis kelamin perempuan dan memiliki kepribadian tertutup. Menurut Thahir (2011) disebutkan bahwa perbedaan penggunaan mekanisme koping pada lakilaki dan perempuan disebabkan oleh faktor fisiologi. Dimana wanita memiliki kecenderungan menggunakan koping yang berfokus pada emosi sedangkan laki-laki menggunakan mekanisme koping focus problem. Pada mekanisme koping focus problem akan menghasilkan koping adaptif. Sedangkan mekanisme koping yang berfokus pada emosi akan menghasilkan koping maladaptif. Hal ini diasumsikan bahwa wanita akan cenderung menggunakan emosi ketika memecahkan masalah dan mengedepankan perasaannya. Selain itu kepribadian yang tertutup menjadikan individu sulit untuk membagi perasaannya. Sehingga akan lebih mudah menyikapi suatu stressor seperti P2KK menjadi sebuah masalah yang rumit.

\section{IMPLIKASI HASIL PENELITIAN}

Implikasi hasil penelitian ini khususnya bagi institusi Poltekkes RS Soepraoen untuk dapat membangun komunikasi dengan orang tua. Sehingga institusi dapat memanfaatkan sumber sumber yang dapat mempermudah perubahan perilaku yang adaptif bagi 
mahasiswa dengan bekerja sama dengan keluarga.

\section{KETERBATASAN PENELITIAN}

Pengukuran mekanisme koping mahasiswa dalam menempuh Program Pengenalan Kehidupan Kampus dilakukan dengan melakukan recall sehingga untuk keakuratan data tergantung dari daya ingat masing-masing responden.

\section{KESIMPULAN}

Mekanisme koping mahasiswa baru sebagian besar adaptif sebanyak 118 $(99,2 \%)$ dan sebagian kecil mal adaptif sebanyak 1 orang $(0,2 \%)$. Hal ini dimungkinkan dipengaruhi oleh umur, pola asuh, pekerjaan orang tua, jenis kelamin dan kepribadian.

\section{SARAN}

Bagi institusi hasil penelitian ini dapat dijadikan bahan informasi untuk memberikan pendampingan serta pemberian informasi yang adekuat sehingga akan mempermudah calon mahasiswa dalam beradaptasi di lingkungan yang baru. Selain itu juga memberikan masukan kepada orang tua untuk memberikan lingkungan yang memudahkan anak tumbuh dengan sikap yang terbuka.

\section{DAFTAR PUSTAKA}

Arikunto, S.(2009). Managemen Penelitian Jakarta. Jakarta:Salemba Medika.

Baramuli, Lidya Eunike.(2014). Fenomena Komunikasi Keluarga Tni Angkatan Darat Asrama Sapta Marga Iv Kelurahan Sario Kotabaru . . Diakses https://media.neliti.com/media/publications 192823-ID-fenomena-komunikasi-keluargatni-angkata.pdf. Tanggal 31 Oktober 2017 pkl 16.53

Bidang Kemahasiswaan Poltekkes RS dr.Soepraoen Malang.(2017). Buku panduan

pengenalan kehidupan kampus bagi mahasiswa baru (PKKMB) Poltekkes RS. Dr. Soepraoen TA 2017/2018 . Malang: Genious Press.

Desmita. (2013). Psikologi perkembangan peserta didik. Bandung: Remaja Rosda Karya.

Herawati. (2015). Pola asuh anak di keluarga militer (TNI) di Batalyon Arhanudse 13 Kubang Pekanbaru. Jurnal FISIP Vo.2 No(2) Oktober.1-6.

Keliat, B. A. (2005). Penatalaksanaan stres. Jakarta: Penerbit Buku Kedokteran EGC.

Lazarus, R.S. and Folkman, S., 1984. Stress, Apraisal and Coping. New York: Springer Publishing Company.

Ma'mun, Jamaludin. (2010) Hand out Psikologi Umum II.UIN Maliki Malang.

Nasir, Abdul. (2012). Dasar-dasar keperawatan jiwa. Jakarta: Salemba Medika. 
Nisrina, Ghina E. (2016). Skripsi:Perbedaan strategi koping stres pada mahasiswa organisasi dan non organisasi di UIN Maulana Malik Ibrahim Malang.

Nugroho, Vitalis H. (2017). Skripsi.

Nursalam. 2013. Pendekatan praktis metodologi riset keperawatan. Jakarta : Salemba Medika.

Stuart, G.W, and Sundeen, S.J. (2000). Principles and practice of psychiatric nursing. Sixth edition. St. Louis: Mosby Year Book.

Stuart, Sundeen. (2012). Buku Saku keperawatan jiwa Edisi 5. Jakarta:EGC.

Taylor, S. E. (2006). Health Psychology (6th ed.). Amerika Serikat: Mc Graw Hill.

Thahir, Andi. (2011). Perbedaan mekanisme koping antara mahasiswa laki-laki dan perempuan dalam menghadapi ujian semester. Penelitian Dosen. Diakses:download.portalgaruda.org/article. php? article $=284027 \&$ val $=5886 \&$ title.

Yuanita, Ratna.S, Sutriningsih, Ani., Catur, Ragil A.W.(2015). Mekanisme koping keluarga menurunkan tingkat kecemasan keluarga pasien stroke. Jurnal Care.Vol.3 No.(2)18-25.

Yusuf, Syamsu. (2012). Psikologi perkembangan anak dan remaja. Bandung: Remaja Rosdakarya. 
